Abstract for COMPLAS 2021 Invited Session IS01:

Advanced computational modelling of wood, wood-based products, and timber structures:

\title{
FE-Analysis of end-notched beams and tenon joints - J-Integral versus cohesive zone modelling
}

\section{Timo Claus - Werner Seim}

Improved wood-based materials, on the one hand, and computer-operated machinery, on the other, enable new types of timber-to-timber joints. Furthermore, new materials, such as laminated veneer lumber with cross-layers made of soft- or hardwood offer new possibilities regarding timber-to-timber connections like tenon and mortise. Experimental investigations have shown comparable failure mechanisms in mode I and mode II for tenon and multiple tenon joints, dovetail connections as well as for end-notched beams. In the field of fracture mechanics different concepts exists to describe the fracture behaviour such as the strain energy release rate, the stress intensity factors and the J-integral method for timber-to-timber joints.

In this study the J-integral was determined around the crack tip in a finite element (FE) model in timber connections. The failure criterion was defined when the $J$-integral equals the energy release rate $G_{c}{ }^{1+11}$ in mixed mode of the timber material (Fig. 1a). A sensitivity analysis showed that the failure load $V_{c}$ was not depending significantly on the initial crack length, the element size, the distance from the crack tip of the chosen contour $\Gamma_{1}$ and the size of the chosen contour.

In the next step, the model was validated on experimental test results of end-notched beams, tenon connections and multiple tenon connections (Fig. 1b). The experimental and numerical results showed very good accordance for different connection size and up to seven possible crack layers (Fig. 1c). Furthermore, a comparison between different fracture mechanic models with strain energy release rates and cohesive zones showed good performance of the new approach.

Afterwards, the FE model using the J-integral failure criterion was used to perform a comprehensive study of geometrical parameters for end-notched beams and tenon connections. Finally, the dataset was used as a basis to develop a engineering model for three types of timber connections.

The evaluation of the $J$-integral allows to determine the failure load due to crack initiation under a mixed mode loading in a linear elastic FE model with pre-defined cracks. The advantage of the J-integral method is the significant decrease of the computing time for extensive parameter studies. The model for end-notched beams, tenon joints and multiple tenon connections is insensitive to common variations of material properties as well as for the choice of the initial crack length. The application on timber structures under pure shear failure or tension failure perpendicular to the grain will be part of future research.

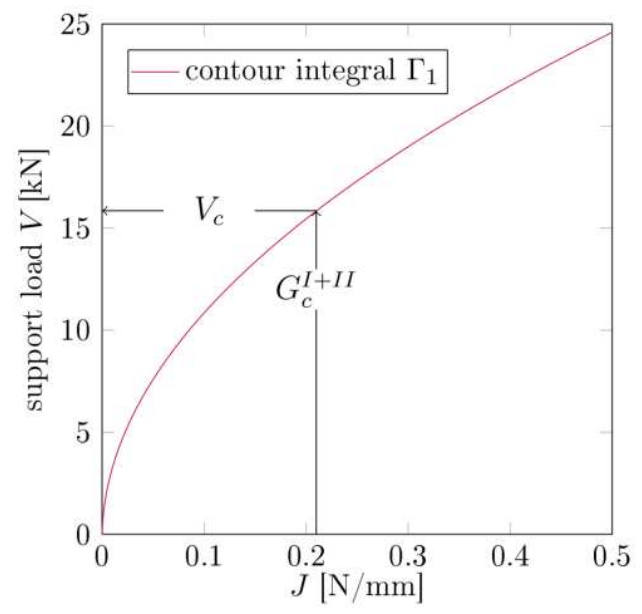

(a)

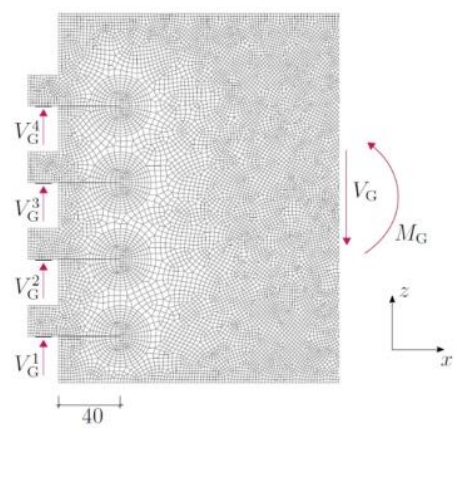

(b)

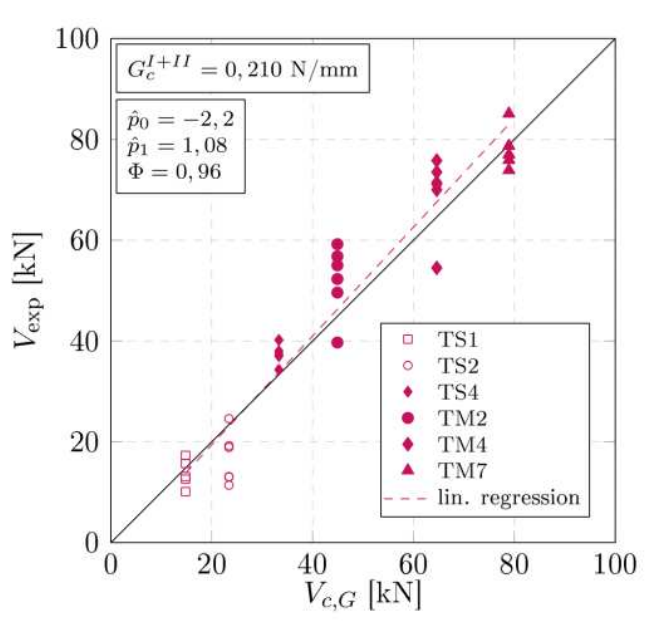

(c)

Fig. 1: (a) evaluation of the J-integral and determination of the failure load $V_{c}(b)$ discretization of a the multiple tenon joint TS4 with predefined cracks and (b) comparison of experimental test results $V_{\exp }$ and results from numerical calculations using the $J$-integral $V_{c, G}$ 